\title{
Sandhoff disease mimicking adult-onset bulbospinal
} neuronopathy

\author{
P K THOMAS, ELISABETH YOUNG, ${ }^{*}$ R H M KING \\ From the Department of Neurological Science, Royal Free Hospital School of Medicine, and the Department of \\ Clinical Biochemistry, ${ }^{*}$ Hospital for Sick Children, Great Ormond Street, London, UK
}

SUMMARY A 32 year old male is described with an onset of upper limb postural tremor in adolescence followed by muscle cramps. Progressive proximal amyotrophy and weakness in the limbs developed late in the third decade. Examination disclosed, in addition, bilateral facial weakness and mild dysarthria. Enzyme studies revealed hexosaminidase A and B deficiency, indicating a diagnosis of Sandhoff disease. Intra-axonal membranocytoplasmic bodies were present in a rectal biopsy. The presentation, which resembled that of $\mathrm{X}$-linked bulbospinal neuronopathy, widens the clinical spectrum for disorders related to $\mathrm{G}_{\mathrm{M} 2}$ gangliosidosis.

The $\mathrm{G}_{\mathrm{M} 2}$ gangliosidoses result from a deficiency either of the hexosaminidase enzyme which hydrolyses the terminal $\mathrm{N}$-acetylgalactosamine from the ganglioside $G_{M 2}$, or of the activator protein for the enzyme. Two major isoenzymes of hexosaminidase are found in human tissues, namely hexosaminidase $A$ and hexosaminidase B (hex A and hex B). Hex A is composed of $\alpha$ and $\beta$ subunits coded for on chromosomes 15 and 5 respectively whereas hex $B$ is composed only of $\beta$ subunits. Thus a mutation at the $\alpha$ locus gives rise to deficiency of hex $A$ and a mutation at the $\beta$ locus to a deficiency of hex $A$ and hex $B$.

Hex A deficiency occurs in Tay-Sachs disease and has also been reported in adult $G_{M 2}$ gangliosidosis. ${ }^{1}$ Hex A and B deficiency occurs in Sandhoff disease. Sandhoff disease usually presents before the age of 9 months with mental and motor regression, visual failure with cherry-red spots, and macrocephaly. Cases of Sandhoff disease with a later onset and protracted course have been described, presenting with progressive ataxia, spasticity and psychomotor retardation in late childhood, ${ }^{2-5}$ as a progressive ataxic syndrome in adult life, ${ }^{6}$ or with spinal muscular atrophy that resembles Kugelberg-Welander disease. We report a new presentation in early adult life,

Address for reprint requests: Prof P K Thomas, Department of Neurological Science, Royal Free Hospital School of Medicine, Rowland Hill Street, London NW3 2PF, UK.

Received 23 December 1988 and in revised form 19 March 1989. Accepted 28 March 1989 mimicking that of $\mathrm{X}$-linked bulbospinal neuronopathy. ${ }^{89}$

\section{Case report}

This 32 year old male had a normal early developmental history. He received speech therapy for a mild articulatory disturbance of dyslalic nature during childhood. He was seen by a neurologist at the age of 15 years because of upper limb tremor and a diagnosis of essential tremor was made. This has persisted. He has been prone to muscle cramps for some years. From the age of 28 or 29 years, slowly progressive proximal lower limb weakness has become evident, accompanied by wasting of the thighs. He has noticed no upper limb weakness and has had no symptoms referable to the cranial nerves. Bladder, bowel and sexual function has been normal.

He has no children or siblings. His father is neurologically normal. His mother has a mild lower limb sensory abnormality related to spinal cord involvement secondary to midthoracic vertebral crush fractures sustained in a car accident. There is no other family history of neurological disorder. His parents are both Caucasian and nonconsanguinous.

Neurological examination revealed normal cranial nerve function except for mild bilateral facial weakness and slight dysarthria. There was no contraction fasciculation of the face. His tongue was normal. In the upper limbs there was mild bilateral proximal muscle weakness and wasting and a postural tremor of the outstretched hands, present during movement. In the lower limbs, there was bilateral quadriceps wasting and moderately severe weakness of hip flexion and abduction, lesser weakness of quadriceps, and mild weakness of the anterolateral muscles in the lower legs. There was no lower limb tremor or ataxia. His tendon reflexes were normal 
Table 1 Hexosaminidase activity in the patient and his parents

\begin{tabular}{|c|c|c|c|c|c|c|}
\hline & \multicolumn{3}{|c|}{ Total hexosaminidase } & \multicolumn{3}{|c|}{$\%$ hexosaminidase $A$} \\
\hline & $\begin{array}{l}\text { Plasma } \\
(\mu \mathrm{mol} / \mathrm{ml} / \mathrm{h})\end{array}$ & WBC & Skin fibroblasts & Plasma & $W B C$ & Skin fibroblasts \\
\hline
\end{tabular}

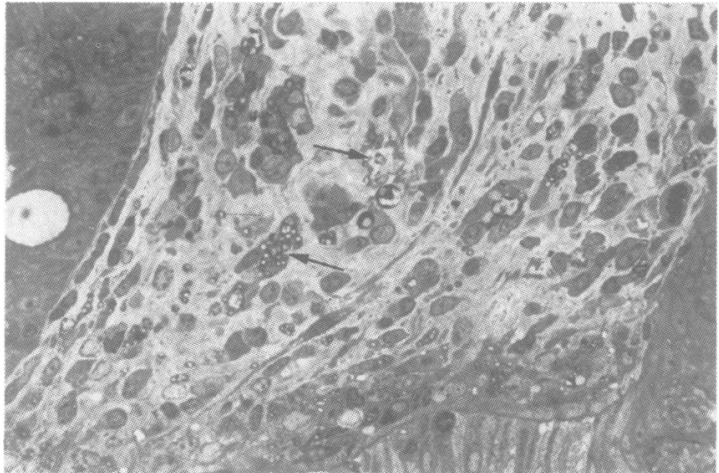

Fig 1 Semithin section of rectal biopsy specimen showing multiple macrophages containing lipid inclusions (arrows). Araldite section, thionin and acridine orange stain, $\times 550$. apart from sluggish knee jerks. His plantar responses were flexor and there was no sensory loss. Examination of other systems was negative. There was no gynaecomastia.

Routine haematological and biochemical studies were normal. There were no vacuolated lymphocytes. His serum creatine kinase activity was slightly increased (219 IU/1; normal < 195 IU/1). Electromyography showed chronic partial denervation in the right deltoid, biceps brachii, first dorsal interosseous, vastus medialis and tibialis anterior muscles. Motor nerve conduction velocity was normal (median $63 \mathrm{~m} / \mathrm{s}$; ulnar $55 \mathrm{~m} / \mathrm{s}$; peroneal $43 \mathrm{~m} / \mathrm{s}$ ). Median, ulnar, radial and sural sensory nerve action potentials were $O$ absent. Central motor conduction time was normal (cortex$\mathrm{C} 8 / \mathrm{Tl}$, magnetic stimulation: right $6.0 \mathrm{~ms}$, left $5.6 \mathrm{~ms}$ ) as was an electrocardiogram.

His karyotype (fibroblast culture) was normal.

Special investigations

Lysosomal enzyme studies revealed a profound deficiency of hexosaminidase activity (table 1) compared with other

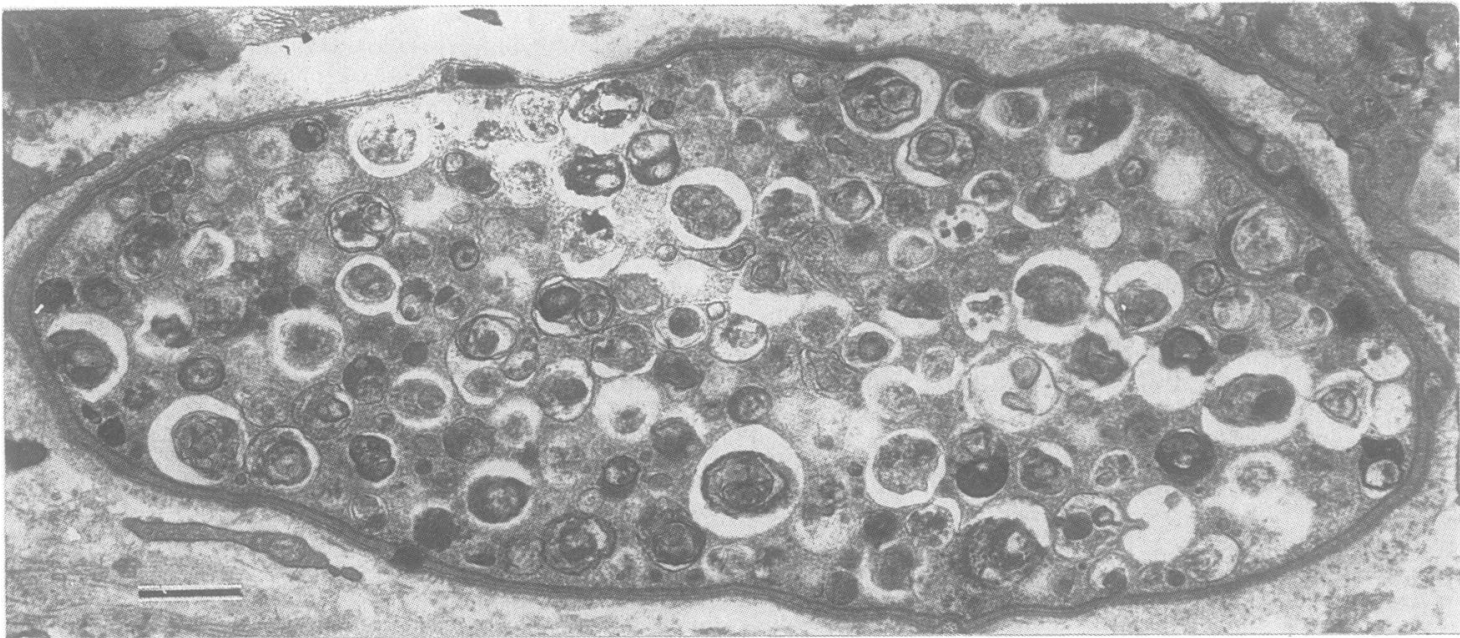

Fig 2 Electron micrograph from rectal biopsy specimen showing an axon filled with multiple lamellar inclusion bodies. Bar = $1 \mu m$. 
Table 2 Clinical spectrum of $G_{M 2}$ gangliosidoses

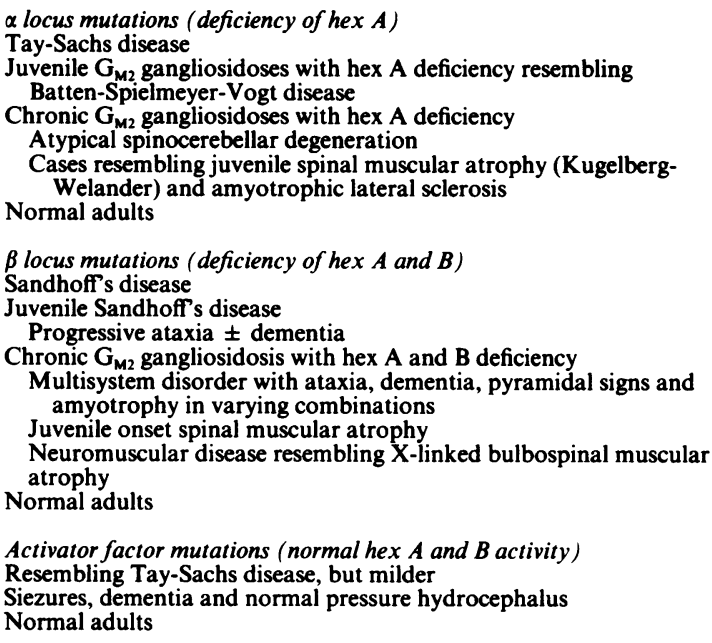

lysosmal enzymes which had activities within the normal ranges, indicating a diagnosis of Sandhoff disease. Hexosaminidase was measured in plasma, leucocytes and cultured skin fibroblasts using the synthetic 4-methylumbelliferyl substrate as described previously. ${ }^{10}$ Urinary oligosaccharides were normal.

\section{Rectal biopsy}

Moderate numbers of macrophages containing PAS-positive material were present in the lamina propria (fig 1). Small numbers of neurons related to the muscularis mucosa contained rounded sudanophilic eosinophilic inclusions which were PAS-negative but which showed positive staining with Luxol fast blue. The appearances and staining reactions were those of a gangliosidosis and consistent with Sandhoff disease (Prof B Lake). Electron microscopy confirmed the presence of multiple concentric lamellar structures within axons (fig 2).

\section{Discussion}

The clinical features in this patient bore a distinct resemblance to $\mathrm{X}$-linked bulbospinal neuronopathy with the early onset of upper limb postural tremor, followed by muscle cramps, limb girdle and predominant proximal limb muscle weakness, mild facial weakness and dysarthria. X-linked bulbospinal neuronopathy was initially considered to represent a "spinal muscular atrophy", but sensory nerve action potentials are depressed or absent and mild sensory loss may be present at times. ${ }^{89}$ Sensory nerve action potentials were lost in the present case, although there was no sensory loss. Gynaecomastia is present in approximately $50 \%$ of patients with X-linked bulbospinal neuronopathy but was not shown by our patient.
Cases of hexosaminidase A deficiency of delayed onset have been described in recent years in whom lower motor neuron involvement has been a prominent feature. In some of these it has constituted the sole neurological manifestation, ${ }^{71-15}$ such cases resembling juvenile-onset spinal muscular atrophy. Our patient most closely resembles that of Case 1 of Parnes et al ${ }^{16}$ in whom postural tremor and muscle cramps preceded limb muscle weakness but in whom sensory nerve conduction was normal. The three cases of Mitsumoto et $a l^{17}$ has a multisystem degeneration with amyotrophy, ataxia, spasticity and mental retardation, one having an axonal sensorimotor neuropathy. The six described by Argov and Navon ${ }^{1}$ also showed a multisystem degeneration, as did those reported by Adams and Green ${ }^{5}$ and Harding et al ${ }^{18}$

The enzyme studies in our patient indicate a deficiency of hexosaminidase $A$ and $B$. The case is thus classifiable as an example of delayed onset Sandhoff disease. An asymptomatic individual has been reported who possessed the homozygous Sandhoff phenotype,${ }^{19}$ but the presence in the rectal biopsy from our patient of intraaxonal membranocytoplasmic bodies of the type that occur in $\mathrm{G}_{\mathrm{M} 2}$ gangliosidosis makes it highly probable that the hexosaminidase deficiency is responsible for his neurological disorder. The higher residual activity in his fibroblasts as compared with patients with the classical infantile form of Sandhoff disease may explain the later onset of symptoms. A case has been described with the Franceschetti syndrome and a significant reduction in hexosaminidase $\mathbf{B}$ in which there was a balanced chromosomal translocation $(5: 13)$ (q11:p11) ${ }^{20}$ The karyotype in the present case was normal.

Of the 23 obligate heterozygotes for infantile Sandhoff disease that we have tested, 21 had either a total hexosaminidase activity or percentage hex A outside the normal range in either plasma, leucocytes or both. The remaining two obligate carriers had both total hexosaminidase activity and percentage hex $\mathrm{A}$ in the overlap range of heterozygotes and normal controls. The mother of our patient had enzyme levels consistent with a heterozygote for Sandhoff disease whereas the levels in his father were within the normal range. Although confirmatory serological studies were not undertaken, the physical resemblances between father and son were so close as to leave no doubt that the stated paternity was correct.

It is possible that the parents possess different gene mutations, only one of which is reflected in altered enzyme activity with the synthetic 4-methylumbelliferyl substrate. The patient might therefore be a compound heterozygote. If so, this could be relevant to his atypical presentation.

Measurement of the hexosaminidase activity in the parents against the natural $\mathrm{G}_{\mathrm{M} 2}$ substrate may be more 
informative, as may DNA analysis. At present, however, no material from the parents is available for further study.

This case widens the already extensive spectrum of clinical presentations that have been shown to be attributable to $\mathrm{G}_{\mathrm{M} 2}$ gangliosidoses (table 2). ${ }^{21}$

We thank Dr Gerald Stern for referring the patient, Dr Nicholas Murray for undertaking some of the electrodiagnostic studies, Professor Brian Lake for examining the rectal biopsy and the Friedreich's Ataxia Group for financial support.

\section{References}

1 Argov Z, Navon R. Clinical and genetic variations in the syndrome of adult $\mathbf{G M}_{2}$ gangliosidoses resulting from hexosaminidase A deficiency. Ann Neurol 1984;16:14-20.

2 Woods S, MacDougall BG. Juvenile Sandhoff's disease: some properties of the residual hexosaminidase in cultured fibroblasts. Am J Hum Genet 1976;28:489-95.

3 Goldie WD, Holtzman D, Suzuki K. Chronic hexosaminidase A and B deficiency. Ann Neurol 1977;2:156-8.

4 MacLeod PM, Wood S, Jan JE, Applegarth DA, Dolman C. Progressive cerebellar ataxia, spasticity, psychomotor retardation, and hexosaminidase deficiency in a 10 year old child: juvenile Sandhoff disease. Neurology 1977;27:571-3.

5 Adams C, Green S. Late onset hexosaminidase A and hexosaminidase A and B deficiency: family study and review. Dev Med Child Neurol 1986;28:236-43.

6 Oonk JG, van de Helm HJ, Martin JJ. Spinocerebellar degeneration: hexosaminidase $\mathbf{A}$ and $\mathbf{B}$ deficiency in two adult sisters. Neurology 1979;29:380-4.

7 Barbeau A, Plasse L, Cloutier T, Paris S, Roy M. Lysosomal enzymes in ataxia: discovery of two cases of late onset hexosaminidase A and B deficiency (adult Sandhoff disease) in French Canadians. Can J Neurol Sci 1984;11:601-6.

8 Harding AE, Thomas PK, Baraitser M, Bradbury PG, MorganHughes JA, Ponsford JR. X-linked recessive bulbospinal neuronopathy: a report of 10 cases. J Neurol Neurosurg Psychiatry 1982;45:1012-9.

9 Sobue G, Hashizume Y, Mukai E, Hirayama M, Mitsuma T. Xlinked recessive bulbospinal neuronopathy: a clinicopathological study. Brain 1989;112:209-32.

10 Brett EM, Ellis RB, Haas L, Ikonne JU, Lake BD, Patrick AD, Stephens $\mathbf{R}$. Late onset $\mathbf{G M}_{2}$ gangliosidosis; clinical, pathological and biochemical studies on eight patients. Arch Dis Child 1973;48:775-85.

11 Jellinger K, Anzil AP, Seeman D, Bernheimer H. Adult $\mathbf{G M}_{2}$ gangliosidosis masquerading as slowly progressive muscular atrophy. Motor neuron disease phenotype. Clin Neuropathol 1982;1:31-44.

12 Johnson W, Wigger HJ, Karp HR. Juvenile spinal muscular atrophy. A new hexosaminidase deficiency phenotype. Ann Neurol 1982;11:11-16.

13 Kolodny E, Lyerla T, Raghavan SS, Seashore G, Fogelson H, Pope HG. Significance of hexosaminidase A deficiency in adults. Neurology 1982;32:A81-82.

14 Dale AJD, Engel AG, Rudd NL. Familial hexosaminidase A deficiency with Kugelberg-Welander phenotype and mental change. Ann Neurol 1983;14:109.

15 Karni A, Navon R, Sadeh M. Hexosaminidase A deficiency manifesting as spinal muscular atrophy of late onset. Ann Neurol 1988;24:451-3.

16 Parnes S, Karpati G, Carpenter S, Ng Ying Kin NMK, Wolfe LS, Suranyi $\mathbf{L}$. Hexosaminidase A deficiency presenting as atypical juvenile-onset spinal muscular atrophy. Arch Neurol 1985;42:1176-80.

17 Mitsumoto H, Sliman RJ, Schafer IA, Sternick ES, Kaufman B, Wilbourn A, Horwitz SJ. Motor neuron disease and adult hexosaminidase A deficiency in two families: evidence for multisystem degeneration. Ann Neurol 1985;17:378-85.

18 Harding AE, Young EP, Schon F. Adult onset supranuclear ophthalmoplegia, cerebellar ataxia, and neurogenic proximal muscle weakness in a brother and sister: another hexosaminidase A deficiency syndrome. J Neurol Neurosurg Psychiatry 1987;50:687-90.

19 Dreyfus JC, Poenaru L, Svennerholm L. Absence of hexosaminidase A and B in a normal adult. N Engl J Med 1975;292:61-3.

20 Balestrazzi P. Franceschetti syndrome in a child with a de novo balanced translocation (5:13) (q11:p11) and significant decrease of hexosaminidase B. Hum Genet 1983;64:305-8.

21 Johnson WG. The clinical spectrum of hexosaminidase deficiency diseases. Neurology 1981;31:1453-6. 